\title{
Invitation aux Voyages
}

Mignonne, allons voir

Si le Népal là-haut

A un ciel aussi bleu

Que le bleu de méthylène.

Sikkim m'était conté

J'en Katmandou pas tant,

J'irai à Bêhobie

En Casamance

Ou au Gobi.

Je prendrai mes cliques et mes claques

Pour aller voir les Kazakhs et les Cosaques

J'irai par la Corée

J'irai par 1'Espagne

Et pourquoi pas le Mexique?

Je sais que le Yucatan

$\mathrm{M}^{\prime}$ attend.

Nous lèverons I'ancre pour la Chine

Nous irons entendre craquer

Le cratère du Krakatoa

Et voir les Chinois de Cholon

Changer leurs chemises chamarrées.

Et de 1à, à Delhi

De 1'Inde goûter les poules et les marrons Pondichéry, Chandernagor

Ma belle chérie, ma Belphégor.

Embarquons pour Madère, 
Laissons les chiens aboyer à Pampelune Et miauler les chattes siamoises de Minneapolis. Connais-tu Tripoli?

Connais-tu Trébizonde?

Tlemcen, Laghouat et Djedjel1i?

La mer d'Aral, la Terre de Feu,

Le Khorassan et 1 'Arbre Sec?

Amie, amie!

$N^{\prime}$ attendons à demain

Voyons dès aujourd'hui

Les mil e coins du paradis.

Mustapha K. Bénouis

The University of Hawaii 